AFRICAN

\title{
The Chinese in Africa/Africans in China Research Network: The role of a virtual network on increasing Africa's "East Asia literacy"
}

\author{
By Yoon Jung Park* \\ Department of Sociology, Rhodes University \\ Grahamstown, South Africa
}

\begin{abstract}
The focus of this special issue of the Africa-East Asia Affairs journal is on "institutions" engaged in East Asia education and learning in Africa. The Chinese in Africa/Africans in China Research Network (CA/AC Research Network, referred to hereafter as the Network) sits somewhere along the margins of this topic - neither a centre nor an institution; without a permanent, physical home; the Network is a sort of global virtual network. It is, nonetheless, worth including in this discussion for a number of reasons. The Network is unique insofar as it is not based at a single institution, but functions in the broader, virtual, digital space and maintains partnerships with various organisations. Network "operations" utilise a closed online network for internal communications (a google group) and an open webspace $^{1}$ to share resources and information with the wider public. It is a membership-based body, with minimal entry requirements, drawing members from around the globe, so that, in effect, the Network's members are self-selected and self-governing, and the Network, itself, stateless. Finally, the Network's inclusion in this special issue is justified by the vital role it has played in strengthening China-Africa literacy through our various activities, not only amongst its member

*Yoon Park is a Senior Research Associate at the Department of Sociology at Rhodes University in Grahamstown, South Africa. Park is also the Convener/ Coordinator for the Chinese in Africa/Africans in China Research Network.
\end{abstract}


scholars and researchers but also amongst policy makers and the wider public in Africa, China, and elsewhere.

\section{History of the Network}

The Chinese in Africa/Africans in China Research Network began its life as a small research working group, founded by a handful of scholars at the conclusion of a public seminar in July 2007, hosted by the Centre for Sociological Research at the University of Johannesburg and the South African Mail \& Guardian weekly newspaper, with funding from the National Research Foundation (NRF) and the Mail \& Guardian. The event, "Chinese in Africa: Race, Relations, and Reflections", attended by over 100 participants was intended to draw attention to the people-to-people dynamics of increasing China-Africa linkages. Following this event, the organisers, Yoon Jung Park and Tu Huynh, both based at the time at the Centre for Sociological Research at the University of Johannesburg, invited some of the speakers as well as other China-Africa scholars to a small, closed workshop to discuss the possibilities of research collaboration ${ }^{2}$. Mutual interest in ChinaAfrica engagements beyond the macro, political-economic sphere - on issues of migration and settlement, labour issues, and relations - served as the glue for the nascent body. At the conclusion of the workshop, we formed a research working group, aimed at studying the various on-the-ground manifestations of the engagements between people in smaller sub-groups.

The first tasks of the research working group included extending invitations to several other early China-Africa scholars not present at the meeting, drawing up a preliminary list and descriptions of proposed research projects, and identifying potential funding sources. Of this preliminary list of proposed research projects, several were carried out while others were postponed due to lack of funding. The South Africa-based team managed to carry out preliminary research on the growing new Chinese migrant communities in South Africa with additional funding from the NRF, Fahamu, and the Faculty of Humanities at the University of Johannesburg ${ }^{3}$. 


\section{AFRICAN \\ EAST-ASIAN \\ AFFAIRS

This second NRF grant also provided sufficient funds so we were able to host a second public seminar and a more substantive closed academic conference to present our research. This was hosted, again, by the University of Johannesburg, on their Auckland Park campus in August 2009. The conference, which involved an internationally publicised call for papers, drew academics from well beyond our initial research working group. Papers presented at this first conference examined Chinese in Angola, Cape Verde, Mali, Senegal, Mozambique, Ghana, Equatorial Guinea, Mauritius, Sudan, South Africa, and Zambia; still others were beginning to conduct preliminary research on the growing numbers of African traders in Hong Kong and Guangzhou. The papers presented at the conference were all based on empirical research and offered early glimpses and thick descriptions of Chinese migrants in several African countries and African traders in China as well as local perceptions of these new migrants. In addition to local media coverage including interviews with several of the presenters, we were also able to publish a selection of the conference papers in a special issue of African and Asian Studies.

At this stage, although we had run through all the available funding, it was clear that there was need and tremendous support for continued networking and further research. Media and academic interest in China's Africa engagements had been increasing, matched by growing interest in the activities of Africans in China. Our small research working group had also expanded at the conclusion of the conference to include members from around the globe by the end of 2009. Beyond the initial South Africa- and Hong Kong-based members of the research working group (who were from the US ${ }^{4}$, South Africa, Australia, the UK, Ghana, Hong Kong, and China), we now had researchers from France, Norway, Portugal, Spain, Sweden and Switzerland, as well as Mauritius and Mozambique.

Given the high levels of interest, we decided to transform ourselves from a research working group into an international research network and through word-ofmouth we continued to grow, add members, and transform our scope of work from a focus on the actual research to broader networking and information-sharing functions. While individual members would find ways to fund their own research, we 
refocused our attentions on facilitating contact and communication both within the group and with others interested in China-Africa relations and issues; in other words, we became a network focused on networking and the dissemination of information.

\section{The work of the Network}

The CA/AC Research Network is a unique group in a growing field of ChinaAfrica and Africa-Asia centres, blogs, and other bodies in that we retain a primary focus on the people-oriented aspects of China-Africa engagement. As we have grown and developed, we have attempted to "institutionalise" or formalise leadership, management, and partnerships. This has meant refining our purpose. As such, we now define our mission thusly:

"to promote cutting edge research, debate, and ideas about China-Africa issues by supporting and encouraging the work and communication of a large and rapidly growing network of international scholars, students, media professionals and practitioners who are involved in short-and long-term field research in or work on Africa and China".

The CA/AC Research Network provides the only independent and international platforms for real time discussions, interactive debates, and insightful knowledge sharing through the use of digital media and conferences. The Network fosters exchange and discussion about the growing relationship between Chinese and Africans by playing a leading role in developing an active community of researchers and experts.

Making the decision to move from direct email communications to a listserv in mid-2010 facilitated the sharing of information. Originally via email and later through the listserv, we circulated media articles on China-Africa engagement; reports and academic publications; scholarship, fellowship and job announcements; and calls for papers. Equally important, however, was our networking and discussion function: the listserv permitted an open, global and largely unmoderated discussion and debate about topics of mutual interest, questions related 
AFRICAN

EAST-ASIAN

AFFAIRS

to field research, and the sharing of insights and opinions amongst colleagues in a safe and neutral space.

In addition to providing a dynamic interactive virtual platform where members meet, debate, inquire, and stay in touch, the CA/AC Research Network participates in and organises conferences, workshops, and events in different parts of the world for face-to-face engagement between our members and with the public. Since our founding we have hosted three public seminars (in 2007, 2009, and 2012) and two conferences (in 2009 and 2012); plans are in place for our third working conference, to be hosted in Guangzhou, China at Jinan University. In addition to the events that we have hosted we have also organised and/or participated in larger international conferences, including those hosted by the International Conference of Asia Scholars/Asian Studies Association (2011), the African Studies Association (2012, 2013, and 2014), International Society for the Study of Overseas Chinese (2009), the Centre for African Studies at the University of Edinburgh (2012), and the Institute of African Studies at the Russian Academy of Sciences (2014) amongst others.

Beyond the virtual engagement through the listserv and the website, and periodic face-to-face engagement of smaller sub-groups of Network members at academic conferences and workshops, the Network has also spurred the birth of two local social networking groups, in Washington, DC in the USA and Johannesburg in South Africa. Sino-Africa DC (SADC) serves the greater Washington, DC area and is the brainchild of Winslow Robertson. Through an electronic newsletter, he and his team circulate information about local events; conference, job, and publications listings often culled from the Network's listserv; and relevant news items with brief summaries and links. SADC also hosts happy hours, lectures and similar events about once a quarter, providing opportunities to meet and network. The membership, which overlaps to some extent with that of the Network, is now over 200, and includes students, members of the business community, international lawyers, journalists, non-profits, think tanks, officials from US government departments and agencies, and officials from African governments. Based on Winslow 
Robertson's accounting, the make-up of the group is approximately 45 per cent American, 35 per cent Chinese, and 20 per cent African.

The Johannesburg group, China Africa Social (CAS), hosts events about once a month or so, involving a speaker and discussions, and appears to have a more business and business networking emphasis. This group was initially started by another member of the Network, Jinghao Lu, who has since left South Africa; it continues to be managed by Patrick Ache and the CAS team. While both of these groups have ties to the Network, they run quite differently and are independently managed. The Network has also been approached by members in Beijing about the possibilities of starting another such group in China's capital city.

Perhaps most importantly, we support and organise the publication of new, cutting edge research and continue to circulate and publicise these publications. Beyond our network, the academic community, and these local networking groups, we aim to share our knowledge, experience, and expertise from the field to a wider interested public through the dissemination of research findings and expert commentary. Our members have published widely in online journals and newsletters, such as Pambazuka News (Fahamu), The China Monitor and the African-East Asian Affairs journal of the Centre for Chinese Studies, and occasional papers for the Global Powers and Africa Programme (encompassing China in Africa) at the South African Institute for International Affairs. Network members provide the media with nuanced perspectives based on grounded research and are regularly cited in the news ${ }^{5}$. In addition to individual member publication of articles in peerreviewed journals and their own books, we periodically undertake the publication of special issues of academic journals focused on China-Africa issues; examples of these can be found in African \& Asian Studies Journal (Vol 69, No 3, December 2010), African Studies Review (Vol 56, No 1, April 2013), and the Journal of Current Chinese Affairs (Vol 43, No 1, 2014).

On a topic that has become fraught with misinformation, rumour and myth, and misperceptions, the Network has played a critical role in supporting researchers and getting new, nuanced and accurate research out to interested audiences. Great- 


\section{AFRICAN \\ EAST-ASIAN \\ AFFAIRS

er visibility and great collaboration with media can only further improve coverage of the complex web of relations between Chinese and African states, companies, and people. Through greater dissemination of short, accessible, and empiricallybased research to media and academic outlets, the Network's members will continue to work toward increasing awareness, improving accuracy, and contributing greater understanding of the complexities of China-Africa engagements.

\section{Membership, leadership and capacity building}

From a small research working group of fewer than a dozen researchers, the Network now has nearly 500 members plus an additional 250 odd members of spinoff groups. While the majority of our members are researchers - from undergraduate students to senior academics to undergraduate and MA students - an increasing number of practitioners and professionals from other fields are also filling our ranks. Amongst our newer members we have public servants, diplomats and consultants; development, environment and international security practitioners; donors and activists; as well as journalists and filmmakers.

Members work on a wide range of issues including migration, labour relations, race, gender, identity, as well as local politics, trade issues, security and environment, and public policy. The Network is also multi-disciplinary, with scholars from sociology, anthropology, history, geography, politics and international relations, economics, and journalism. Our members include some of the foremost scholars on China/Africa relations, representatives of many of the China-Africa focused research centres and projects around the globe, as well as Masters' and $\mathrm{PhD}$ candidates involved in cutting-edge field research. Finally, the Network's membership has become truly global with members from across Asia and Africa, the Americas, the United Kingdom (UK) and the rest of Europe.

When it became clear that the Network was in the throes of expansion, Park and Huynh recruited a small team to serve as a steering committee. The steering committee serves as a sounding board as well as a preliminary recruitment point for all the work involved in maintaining the Network. Together the small team has served as the core for several larger teams that have coordinated panels for international 
conferences, organised several Network conferences and public seminars, conducted fund raising, provided content for the website and other Network documents, and generally provided Park with much needed support, mentorship and guidance. The steering committee, as of 2013, includes Yoon Jung Park, Barry Sautman, YAN Hairong, Heidi Østbø Haugen, Jamie Monson, Bob Wekesa, and Solange Guo Chatelard; between us, we have institutional affiliations in the US, China, Hong Kong, Kenya, South Africa, Norway, France and Germany.

The Network has been closely involved with the Social Science Research Council, based in Brooklyn, New York since 2012. With generous seed funding from the Henry Luce Foundation, the SSRC has been assisting the Network in establishing a web space to amplify our impact and share resources with a larger audience. Since the launch of the China Africa Knowledge Project ${ }^{6}$ we had been able to share blog rolls, curricula, bibliographies, new publications, and news of Network members in the news, as well as featured researchers with the general public. A research database should be available online shortly. In addition to our joint work on this exciting new web space, the Network is also collaborating with the SSRC on broader field-building work together with a working group on China-Africa. The working group "is a cross-regional, inter-disciplinary group of leading scholars. It helps guide the China-Africa Knowledge Project's planning process to build more generative connections between scholars across disciplines and regions relevant for understanding Africa's engagement with China and other emerging powers. This initial focus on China and Africa will serve as a model to explore new narratives and relationships in a changing global order".

With the SSRC and Yale University, the Network co-hosted a conference in November 2013 at Yale. One of the key issues raised at a smaller workshop held after the conference involved capacity issues; participants from China and Africa mentioned the unevenness of capacity. All agreed that many of the leading scholars in the sub-field appeared to be based in the West. To this end, several participants suggested the following:

- $\quad$ build the capacity of African tertiary institutions 
AFRICAN

EAST-ASIAN

AFFAIRS

- $\quad$ engage in policy-orientated research

- $\quad$ build bridges between institutions, scholars, and civil society actors

- $\quad$ support summer school programmes such as those offered at CODESRIA

- $\quad$ increase opportunities for research exchanges between Chinese and African scholars, particularly ones that encompass field research opportunities

- $\quad$ create opportunities for junior scholars to write and research collaboratively across disciplines, skill sets and languages in order to shape the conceptual framing of concepts and theories

Clearly, this discussion dovetails with the concerns of this special issue especially regarding African capacity and interests on Asia-related issues. The Network aims to maintain its involvement in these discussions and find ways to contribute to capacity-building where needs are identified. Collaborations and partnerships as well as continued financial support are critical to all of these efforts, and these are discussed below.

\section{Partnerships and support}

The CA/AC Research Network owes a great debt to two institutions in South Africa. The first of these was the Centre for Sociological Research (CSR) at the University of Johannesburg (UJ), which served as the birthplace and first incubator for the Network. Both Park and Huynh were employed at the CSR, which, as a research centre, allowed greater time and resources to be spent on research, thinking, and writing because we had no teaching responsibilities. We also had the support of Peter Alexander, the Director of the CSR and, for a time, several of the more senior administrators at UJ who encouraged us to develop this new research area. With Alexander's assistance and contacts we were able to successfully raise funds from the South African NRF to conduct the preliminary research, host the 2007 and 2009 events, and establish the research working group.

Our second host institution was the Sociology Department at Rhodes University. 
Kirk Helliker, the Head of Sociology, arranged a research affiliation for Park. It also helped that Huynh managed to receive a Mellon award for a post-doctoral fellowship, which was also supported by Helliker. Rhodes is also home to a vibrant, new Confucius Institute (CI) under the leadership of Marius Vermaak; the CI also served as host and partner for specific events at Rhodes. Through the Network-Rhodes partnership, we were able to design and deliver several courses on China-Africa relations to mostly Sociology and Politics students. Beyond course development and teaching, we have helped to identify and attract senior ChinaAfrica scholars to several events and symposia at the University, and encourage a growing number of Rhodes scholars and students to pursue research on ChinaAfrica issues. The highlight of Rhodes' China activities is their "China Week", which is organised by their CI and held annually; "China Week" typically involved a keynote speaker, art exhibits, and seminars.

It is also worth mentioning here that while we have not formalised partnerships with them, two other South Africa-based institutions have been ever present in the life of the Network; these are the South African Institute for International Affairs (SAIIA) based in Johannesburg and the Centre for Chinese Studies (CCS) at Stellenbosch University. Paula Cristina Roque, a former SAIIA researcher, and Nastasya Tay, a former researcher for the CCS, both attended the very first meeting where the idea for establishing the research working group was first raised. The Network has worked closely with both institutions over the years, and we will continue to discuss ways in which we might collaborate in future.

In terms of conference and event collaboration, we have thus far been incredibly fortunate to have generous co-hosts and sponsors. For events in 2007 and 2009 the Network worked with University of Johannesburg and received funding from the Faculty of Humanities as well as the NRF. Since 2010, the Confucius Institute at Rhodes University (CIRU) has hosted a China Week as well as other once-off symposia and seminars; the Network has worked in collaboration with them throughout the years. In 2012, Monash University-South Africa and their home institution in Australia hosted us in Johannesburg; this conference also benefited from some generous support from the American Council of Learned Societies 


\section{AFRICAN \\ EAST-ASIAN \\ AFFAIRS

through their Chiang Ching-kuo Foundation's Comparative Perspectives on Chinese Culture and Society grant. The next Chinese in Africa/Africans in China conference is currently being planned for December 2014; this time our partners and hosts will be the School of International Studies/Academy of Overseas Chinese Studies, at Jinan University. Finally, we are already in discussion with possible hosts for our 2016 conference; at present these include Rhodes University in South Africa as well as institutions in Kenya and Ethiopia.

Our current partnership with the Social Science Research Council (based in New York) is different from those with our university partners insofar as the seed funding from the Henry Luce Foundation and the nature of the SSRC itself creates a different sort of engagement. The SSRC has, in the past, supported networks such as ours to flourish and eventually become independent, serving as a sort of incubator. Funding and support has already resulted in a further expanded membership, through the increase in the visibility of our work via the recent launch and continued development of a web space, which provides additional platforms for engagement on China-Africa issues. We look forward to the additional year (and possibly another) of partnership with the SSRC to continue to build on the work that we started in July 2013.

Finally, we are engaged in preliminary discussions with the Wits China-Africa Journalism Project, University of the Witwatersrand and the School of International Studies/Academy of Overseas Chinese Studies, at Jinan University about possible partnerships. We will continue to explore these as well as other potential collaborations.

While all of these institutional linkages and partnerships are crucial to the Network's work, we believe that one of the reasons for the Network's continued vibrancy and relevance is that it remains, largely, a virtual network; this provides a democratic and open forum, wherein students, senior scholars, journalists and practitioners based around the world are free to engage in dialogue, ask questions, and contribute their thoughts. The lack of a 'home' is, in some ways our greatest strength and possibly our biggest challenge. This and other matters concerning the 
future of the Network are discussed in the next section.

\section{The future of the Network}

Some of the Network's greatest advantages or strengths also present our greatest challenges, as is the case with our current lack of physical home. With the Google group listserv and the web space up and running, there are unlimited opportunities to share information and amplify our impact. Increasing numbers and quality of online publications, including peer-reviewed, academic journals provide opportunities for member researchers to get cutting edge research out to audiences quickly and efficiently. Institutional digital platforms such as those provided by SAIIA and the CCS, as well as others, also provide opportunities to share shorter essays, working papers, think pieces or opinion/editorial essays. With Skype and email as well as other, newer channels of electronic communications, we can speak to one another and even hold steering committee meetings across multiple continents and time zones. The global and virtual nature of the Network also allows us to be stateless and attempt to work outside the boundaries of nation-state and government influence. However, a lack of a permanent, physical home will also raise challenges to fundraising and financial management, as funds must be deposited, taxes and fees paid, somewhere. Thus far, we have managed to bypass these issues by working with partner institutions; however, the Network's steering committee and members will eventually have to grapple with this question of a physical "home" or perhaps multiple "homes".

Our rapid and recent growth is also a testament to the power of "word of mouth" as well as continuing interest in all things related to China-Africa. Alongside our tremendous growth in numbers, we have also become an increasingly diverse group. This has also meant that what was once a smallish group of social and political scientists with a relatively narrow interest in the human aspects of ChinaAfrica engagement who had all met at one point or another has now a much larger body of individuals from a much broader range of countries, professions, languages, and disciplines. On a few occasions this has resulted in divisive and abrasive exchanges on the listserv. Fortunately, these heated and highly fraught discus- 
AFRICAN

EAST-ASIAN

AFFAIRS

sion chains have been few and most of our members remain respectful and collegial. As the Network continues to grow, we will have to find ways to mitigate the differences and perhaps address language issues. All new members are asked to read and agree to a sort of code of conduct. Periodically, the listserv manager sends out reminders of these simple guidelines. The language issue is something that we have not yet tackled directly. Nearly all of the exchanges on both the listserv and the webspace are conducted in English; however, we have discussed the possibility of providing translations for sections of the webspace into Chinese and French. There are obviously costs involved in professional translations, but we will remain mindful of this language and communication issues.

The Network's steering committee has plans to meet up in a face-to-face strategic planning session in the margins of the December CA/AC conference at Jinan University. Here, we hope to discuss ideas to secure further and more sustainable funding; on-going and new institutional linkages with partners Africa, China, and the West, including those with the SSRC, Rhodes University, the CCS, SAIIA, Jinan University, and the Wits China-Africa media project. Also on the agenda are our plans for publication based on the December 2014 conference, other ideas for increased and broadened dissemination of research, and future workshops and conferences. Pending further funding we also have a number of projects and proposals for our future; these include collaborative research projects, fellowships and grants for (post-) graduate research as well as short-term writing or reading workshops; a pot of funds for those in need of conference travel funding; the possibility of a Network journal; and further development of online resources, including some sort of digital forum.

\section{Conclusion}

The emerging field (or sub-field) of China-Africa studies has developed in subsequent waves or generations. There were, of course, a few early scholars of ChinaAfrica, who focused on relations during the Cold War up to the end of the $20^{\text {th }}$ century - Phillip Snow, Bruce Larkin, and George Yu, amongst a handful of others. A second and early wave of scholars picked up on shifts in China's attentions 
to the African continent and these would include Chris Alden, Deborah Brautigam, LI Anshan, HE Wenping, Jamie Monson and Elizabeth Hsu. However, the numbers and the levels of interest remained relatively limited and did not include any significant number of Africans until after the Beijing Summit of Forum of ChinaAfrica Cooperation (FOCAC) in 2006. Even until about 2010 there were few actors or activities in the emerging Asia-Africa field in African academia and most of these appeared to be concentrated in South Africa.

Early actors in the sub-field included, of course, the Centre for Chinese Studies, which had been founded in 2004, and the South African Institute for International Affairs, which through the tireless work of Chris Alden was beginning to marshal some focus and funding to China-Africa issues. The Centre for Advanced Studies of African Society (CASAS) and the Institute for West Asian and African Studies (IWAAS) of the Chinese Academy of Social Sciences (CASS) has hosted an early China-Africa conference (also in Johannesburg), and published selected papers in an edited volume in 2007. The Institute for Global Dialogue had pulled together a few publications, under the leadership of Garth le Pere. The Centre for Conflict Resolution (CCR) was also involved in an early conference, also in 2007, which resulted in the book, Crouching Tiger, Hidden Dragon? Africa and China, edited by Kweku Ampiah and Sanusha Naidu. Naidu moved on to Fahamu and continued to support China-Africa research. The Network is proud to be part of this early group of actors in the continuing development of China-Africa research.

While we continue to struggle with funding, there is no shortage of interest, talent, or need. As an independent Network, we hope to maintain our contribution to Africa's growing literacy on Asia and specifically China and the Chinese migrants who venture to the African continent.

\section{Endnotes}

1. See http://china-africa.ssrc.org/caac-research-network/ 


\section{AFRICAN \\ EAST-ASIAN \\ AFFAIRS

Issue 3

2. This preliminary group of researchers included YAN Hairong, Barry Sautman, Karen Harris, Paula Cristina Roque, Darryl Accone, and Nastasya Tay as well as Tu Huynh and Yoon Jung Park.

3. Other research teams carried out their research with funds from their respective institutions.

4. US refers to the United States of America

5. See http://china-africa.ssrc.org/caac-research-network/network-in-the-news/

6. See http://china-africa.ssrc.org/ 